\title{
Aesthetic Characteristics in Ba Culture
}

\author{
Lei Ma \\ Ba Cultural Research Institute, Sichuan University of Arts and Sciences, Dazhou, China \\ Email: historyof@aliyun.com
}

How to cite this paper: Ma, L. (2020) Aesthetic Characteristics in Ba Culture. Open Journal of Social Sciences, 8, 251-261. https://doi.org/10.4236/jss.2020.89020

Received: August 24, 2020

Accepted: September 22, 2020

Published: September 25, 2020

Copyright () 2020 by author(s) and Scientific Research Publishing Inc. This work is licensed under the Creative Commons Attribution International License (CC BY 4.0).

http://creativecommons.org/licenses/by/4.0/

\begin{abstract}
The Ba cultural elements can still be summarized and analyzed by their relics and the Tujia culture passed down to now after they disappeared. Here is a preliminary summary of the aesthetic characteristics of Ba culture through the form of Ba people's tombs, utensils, songs and dances. It reflects the beauty of primitive simplicity, abstraction of animal worship, spirituality advocating witchcraft, worship with fight and cooperation, flexibility and roundness, and compatibility from diverse sources.
\end{abstract}

\section{Keywords}

Ba Culture, Aesthetics, Characteristics

\section{Introduction}

Although the Ba people and their culture have disappeared in the long history of mankind, from the legacy or cultural elements of the handed down, many marks left by the Ba culture can still be seen. More important ancient relics such as Xiaotianxi, Luojiaba, Chengba and other various cultural sites scattered in Chongqing and East Sichuan, and so on. The modern characteristics of the Ba people are deeply embedded in the lives of the local Han and Tujia families living. The analysis of these marks is conducive to the Investigation and speculation of Ba culture. Ba culture is a culture that is mainly based on fishing, hunting and salt industries, and is still martial and constantly migrating, the artistic achievements in its culture are relatively lower than those of simple farming or pastoral culture which have close relations with foreign cultures. But as Hegel said: "Beauty is the perceptual manifestation of ideas" (Hegel, 1979). Beauty is still inadvertently reflected in all aspects of Ba culture. As far as aesthetics is concerned, rich aesthetic elements with unique cultural characteristics can still be found in Ba culture. These elements are mainly reflected in their tombs, the utensils they used and the dances they left behind. For the beauty in these art 
forms, the author has analyzed in some papers. From these specific forms, the unique aesthetic characteristics and aesthetic principles of the Ba culture can be summarized.

There is not much discussion on the aesthetic theories of the Ba people and the Ba culture. Only a few papers on the aesthetic culture of the Tujia people and some general introductions scattered in archaeological reports and aesthetic works are available for reference, but they are all unclear. For example, in the book History of Painting Arts in the Yangtze River Area (Shao, 2005), there is only told a little about this culture in the narrative of Bashu culture. From the existing works on the study of the art of Ba culture, the main focus is on the following aspects: The first is tracing the origin and discussion of the aesthetic characteristics of the Ba people's era, the second is an analysis of the musical aesthetics of the Ba culture and music, especially the Bayu dance, the third is the research on the bronze art unearthed in $\mathrm{Ba}$ area. In general, the study of the aesthetic factors contained in the Ba culture is still in the exploratory stage, and the research field needs to be expanded and discussed in more depth.

This article is a preliminary summary of the aesthetic characteristics and principles in the $\mathrm{Ba}$ culture during the pre-Han Dynasties times. By combing through the historical documents, relics and legacy of the Ba people, the common features are summarized. In general, the aesthetic characteristics of the $\mathrm{Ba}$ people mainly include the following aspects.

\section{The Beauty of Primitive Simplicity and Nature}

Perhaps it is because that Ba people still live in the primary stage of fishing and hunting production, or because that they may always be in constant migration, the Ba people's lifestyle restricts their artistic creation. Whether in utensils or dance styles, the Ba people reflect the original and rustic side. In the life utensils of the Ba culture, no matter whether it is pottery or bronze, there are rarely engraved patterns on the body of the utensils, reflecting the more practical features. Even objects such as fus, mous, and chunyus, which are very important for the lives of the Ba people, are not decorated at all, and some only have the form of rope-shaped vertical ring ears or tiger-shaped buttons. This should also be regarded as practical purposes to facilitate gripping or hanging, not for purely beautiful decorative purposes. This simple style is in sharp contrast to the complex patterns on the Central Plains and Chu-style bronzes unearthed in the same place, even in the same tomb. This sense of beauty in practical use also embodies the Ba people's characteristic of simplicity in beauty.

And for practical purposes, the Ba style weapons are mostly short and sturdy. The artifacts commonly found in the tombs of the Ba people, whether they are bronze swords, dagger-axes, or spears, the weapons are all very short, indicating that as a sturdy to fearless martial arts group, the Ba people are more used to fighting at close range. Bronze swords are used for puncturing, dagger-axes are used for back-cutting and so on. As the most cherished carry-on items, these 
weapons of the Ba people were still relatively complete today. Although they are not as sophisticated as Chu culture weapons, they still give people an endless aftertaste.

Among the Ba people's burial items, there are few purely as decorative items, and if any, their shapes are relatively simple and small. Some artifacts such as bracelets, earrings, and bells only appear in few tombs. They are mostly plain and no many decorations on them. Others are simply bent from copper bars or wires. This shows that the Ba people have a preliminary aesthetic concept and taste, but facing the basic needs of survival, the meaning of these concepts for the Ba people is not more basic than the need for clothes and food and winning in battle.

According to the existing Tujia dance, the dance movements of the Ba people should look relatively simply and show a rustic style, but it is not very easy to finish it. There are very few props for these dancers, even without any props. The dancers just show the dance posture by constantly shifting or flapping with hands and feet. The costumes used in these dances also reflect the primitive simplicity. For example, the props in Maogus and Muddymen dance are just straw skirts woven from straw, hats made of grass or leaves, and Maogus dancers also have a stick, which is used in dance to refer to the spears for hunting, sticks for carrying prey, etc. It can be said that long whips in Peking opera represent the similarities of thousands of troops and horses, but the stick props in the Maogus dance have more functions. Both of these dances expose part of the dancer's body and feet to highlight the ancestral style of the ancestors. Although the funeral dance and the Hand-waving dance have been separated from the original form of dancing wrapped in grass, they still retain the basic movements and simple forms of the ancestors. Throughout the dance, people just beat a certain rhythm with gongs and drums. The dancers don't have any instruments or props to use, but they repeat several important movements in the flashing movements of their feet and the constant transformation of the hand shape, and use these several movements to string the entire dance. Although these dance movements are very simple and monotonous, they still have an original special beauty, and the coordination of hands and feet and the understanding between people are also difficult to achieve in a short time, which makes the seemingly simple dance not easy. Another feature of these dances is the side-by-side form of simultaneous movement of the hands and feet on the same side, which is not seen in the Central Plains region. Because these movements violate the movement rules used by the human body, it is not easy to grasp. The funeral dance is accompanied by singing accompaniment, while the Hand-waving dance only has some simple monophonic yelling. In these dances, it only plays a role in enhancing the dance effect and rhythm, but the effect is still shocking and causes an endless aftertaste.

The $\mathrm{Ba}$ people live in a mountainous environment, surrounded by high mountains and gurgling water. Their lifestyle is also natural and simple. The relics of the Ba people seem to have only been found in several sites such as Luo- 
jiaba, but the exact style and structure of their residences are still uncertain $(\mathrm{Yu}$, 2018). It is relatively certain that the Ba people's architectural form should be relatively simple, and there will not be a tall and fixed architectural model that stands on the plain like those on the Central Plains or Chengdu Plain. This is consistent with the continuous migration characteristics of the Ba people. The tombs of the Ba people are generally built on the flat ground surrounded by the water, which is what the locals call the "Bazi (which means dam)", or built on the cliff, which is called the "hanging coffin" in later generations. This is different from the Tujia cemetery built on the mountain by later generations, but the Tujia cemetery still has to find a flat ground on the mountain for burial. The tombs of the Ba people excavated on the flat ground are characterized by narrow and long lengths, and the length of the tombs shrinks according to the height of the tomb owner and the number of funeral objects. This may be due to the tradition that the nobles and warriors in the high ranks of the Ba people were buried in boat coffins. Others used narrow and long graves even if they did not use the boat coffin as a burial tool. Among the coffins unearthed in Ba region, some are used objects, some are not. There should be some differences in the middle. Most of these cemeteries are concentrated on the inner side of the river, and the head of the tomb owner is also mostly perpendicular to the river bank, expressing the desire of the $\mathrm{Ba}$ people to go to the ancestral land with the boat. The hanging coffin high above the cliff may tell another story. But no matter what kind of tomb form, all pay attention to the beautiful scenery, wide view and flat sleeping place of the dead. This funeral concept of living in harmony with nature should also be a manifestation of the Ba people advocating the beauty of simple nature.

\section{The Beauty of Abstraction of Animal Worship}

There are only a few kinds of animal patterns used by the Ba people on utensils, that is, tigers, snakes, and winged birds. This is in sharp contrast to the numerous animal patterns in the surrounding Chu culture and Shu culture. These animal patterns are different from the Huaxia people's beauty in the aggressive plane abstract patterns, and also different from the Dian people's beauty in the three-dimensional casting image that imitates reality. The animal totem patterns in the $\mathrm{Ba}$ culture seem to be somewhere in between Huaxia and Dian culture Whether it is the image of a tiger with a big mouth, or the image of a winged bird flapping a single wing, these animal forms are between seemingly and not, realistic and abstract, which transforms the ideal animal image in a moment.

Among these patterns, except for a few full-length depictions, most of them highlight local features. The lines are mainly line-inscribed, and it is rarely seen to be embossed. It's hard to see the form of round carvings on the Ba bronzes except those on Chunyu. The decoration has simple figures with complex lines, but it is not as complicated as the patterns in the Chu culture which the depiction of animals is very vivid to the extreme. 
The Ba people also imitated animal images in their dances. The earliest such as Maogus in the open field, through the dancer's body movements, imitating the process of animal jumping, escaping and being captured. Funeral dance is the interpretation of tigers, birds and other animals' behaviors through body language in a limited space. Dancers are sometimes calm and serene like "Rhino Watches the Moon", sometimes tumbling and jumping like "Tiger Goes Down the Mountain", sometimes contracting their bodies like "Tiger Hug", sometimes opening and closing like "Phoenix Spreading Wings", sometimes witty and humorous like "Bull scratching an itchy", Sometimes flexible and elegant like "Swallow holding mud in mouth", these simple but difficult movements in fact win the laughter and applause of bystanders. In addition to imitating battlefields and production scenes, Hand-waving dances also have some movements that should be based on imitating animals.

It can be said that the mimicry of animal forms not only originates from the spirit of the Ba people admiring nature, but also from the observation of animals and the awe of animal gods or totems. This kind of emotion and belief are inseparable from metaphysical ideology.

\section{The Beauty of Spirituality and Advocating Witchcraft}

The Ba people's reverence for their ancestors and gods is pious and natural. This near-faith feeling is reflected in all aspects of the Ba people's lives. They not only shape or sculpt ancestral totems on utensils, but also express awe and love for ancestors and gods in dance and singing, getting educated and nurtured by beauty after pursuing it.

Although the Ba people rarely produced the complicated patterns on the daily objects, it is easier to produce the impression that they were more practical than even the simple ethnic group, but on a class of utensils, they had fully displayed the gift of beauty. These were weapons that they used and carried daily, and were buried with them after death. These bronze swords, dagger-axes, and spears are engraved with tigers, birds, palm and heart patterns, etc. This is not entirely out of the pursuit of beauty by the Ba warriors, but it is likely because they represent different compositions of the Ba people. The Ba people used these patterns on their weapons, and hoped to use these totems' divine power to achieve victory in battle. These patterns were very carefully portrayed because they were out of the piety of the hearts, and the images are still vivid in thousands of years. The pattern on each weapon is different, even the most used and most similar tiger pattern, each with its own style. This shows that these patterns are not produced in batches by professional craftsmen. And every Ba warrior's tomb with weapons would be found small carving tools such as carving and sharpening knives at the same time, which seems to enlighten us: these totems are probably carved out by the $\mathrm{Ba}$ warriors one by one. It is hard to imagine that such fine patterns will come from the hands of these warriors who were killing others. The descriptions of these patterns are very complicated and vivid, some are concise without losing 
their authenticity, some are integrally portrayed, and some are protruding parts of the body, showing that the writers were not only good at observing everyday things, but also had unusual art Cell. This can only be explained by the piety and spirituality that comes from faith. The ornaments on these weapons had experienced a lot of killing impacts and bloody infestations. The patterns on them are still as bright as before, and one cannot help but doubt that they have been engraved at any time. From this point of view, the Ba warriors are also highly accomplished carving artists.

The Tujia people's dance was inherited from the Ba people's dance, and it is also a model of worshiping the witch and worshiping the priest. Needless to say, dances like Maogus and Muddymen dance are full of mystery of primitive witchcraft and artistic tension. Maogus uses the number of head braids to determine whether the player is a human or an animal, that is, singularly represents humans, and even numbers represent animals, which seems to indicate that in the Ba people's concept, humans and animals are the same species. Unlike the use of straw in later generations, the early Ba people should have used the grass that was obtained from nature to make a grass skirt to cover the body, smear the body with mud, and express their emotions with a primitive and rough voice. In addition, other Ba dances, such as funeral dances and Hand-waving dances, also express good wishes for the dead and the entire ethnic group through the simulation of natural creations. In general, the dance of the $\mathrm{Ba}$ people imitates all kinds of creatures in nature with movements, uses dance as a medium of witchcraft, and communicates with the real life in an abstract way to achieve the state of oneness and unity of nature.

\section{The Beauty of Worship with Fight and Cooperation}

Starting from the Oracle bone inscriptions of the Shang Dynasty, the Ba people and their spirit of martial arts had left a strong stroke in the Central Plains. From Shang to Han Dynasty, the Ba people were known for their ability to conquer good wars. Even in the later Wei, Jin, Southern and Northern Dynasties, and other eras, although the descendants of the Ba people changed their ethnic names, their martial arts persisted. Following the use of force makes them use the utensils and dance movements they embody everywhere, such as bravery and masculine beauty.

The Ba people's dance has a lower center of gravity due to curved legs, which is conducive to making movements such as rolling, jumping, etc., and also makes the movements more flexible and diverse. Taking the simplest Muddymen dance, for example, many of the movements are slapping the dancers' bodies and have a sense of rhythm. This requires not only the coordination of hands and feet, but also the control of the beats. The History of Sui Dynasty recorded that when Ba people circumvented the coffin at the funeral, "When someone died, the others put the corpse in house, the neighborhood boy, each holding Bows and arrows sang around the corpse, with the arrow buckling the 
bow as a festival. The lyrics said funny stories to the end, which was probably the elegy of the present" (Wei, 1973). This kind of "holding bows and arrows sang around the corpse", obviously needs a group of people around the coffin, while striking a certain rhythm with the bows and arrows, it is impossible to finish it without mutual cooperation. Songs were sung around the coffin while holding bows and arrows. Although the words used in them became incomprehensible because they are mixed with many traditional Ba people's voices recorded in Chinese, they can still appreciate the Ba people from these epics singing the bravery in battle and the hardship on the way to migration. One of the side effects of warlike is to make people optimistic. The Tujia Sa'er He, which is famous for dancing funny in the funeral and expresses the emotion of not being sad, is really derived from the Ba people's funeral dance. The aforementioned example shows that the funeral dance in the Sui Dynasty has formed this form of "lyrics saying life is fun" even earlier. It expressed the brave spirit of the Ba people, which was in the same line as the Ba people's custom of martial arts. They even looked death as a way to ancestors and a means of happiness, revealing some ideological connotations similar to later Chinese Buddhism and Taoism. Of course, in these dances, there are more scenes of fighting, the movement amplitude and strength are larger, and the brave and fearless masculine beauty is expressed.

In the military, emphasis is placed on tactical cooperation, which is manifested in dance movements, that is, coordination of hands and feet must be in place. Dancing along the side is not an ideal form of dance for the Hans, but in fact the requirements for hands and feet coordination are very high. In funeral dance and Hand-waving dance, there are mostly doubles, fours or even group dance movements. In the double dance movement, both dancers' hands and feet are opposed, not only to keep up with the drumbeat and rhythm, but also to intersect each other and to avoid touching each other. Sometimes they cooperate with each other and use their power to make difficult movements such as rolling, jumping from a height, etc. The four-person dance is more difficult. Compared to the two-person dance, there are more movements of jumping to each other's position. These movements are very important for the cooperation of the dancers. They should be a simulation and exercise of the tactical cooperation of the $\mathrm{Ba}$ warriors during the war.

Among the utensils used by the Ba people, in addition to the utensils with obvious cultural characteristics of Central Plains, $\mathrm{Chu}$, and Shu obtained through various means, weapons are the most sophisticated. Except that there are a few bronze rituals and living utensils buried in the tombs of the Ba nobles, indicating that they also use these utensils in their lives, the general daily necessities of the Ba people are mainly pottery. Correspondingly, the key parts of their weapons are all made of bronze, including dagger-axe's head, spear head, sword body, arrowhead, as well as the carving and sharpening knives used to repair these weapons. These weapons are not only beautifully crafted, but also have decorative 
patterns that are rare on other utensils. These patterns reflect the principles of practicality and simplicity in the Ba culture. The patterns exaggerated and the lines complicated, they reflect the other side of the Ba people's aesthetic sensibility and express the tireless praise and pursuit worship of ancestors, totem, and witchcraft. All of the pursuit is only to win in battle. The Ba people's simple thinking of winning is achieved through these complicated patterns. Here, the beauty of simplicity and complexity is combined to form the aesthetic characteristics of the Ba culture for the purpose of advocating military force.

\section{The Beauty of Flexibility and Mellow}

The Ba people is a martial people in the impression all the world, and their utensils should be as strong as their national characteristics. But among the utensils actually used by the Ba people handed down, they exhibited artistic characteristics that were different from their national characteristics, that is, they were mostly round or curved. In addition to bracelets, bells, and other round ornaments, other daily objects are also known for their roundness. This is different from the central and western regions of Chinese Central Plains where tripods and fus, mainly in the shape of square, are used, while the eastern region mainly uses dous, tripod lis, etc., which are mainly oblate shaped.

In the tombs that are considered to be typical $\mathrm{Ba}$ culture, the artifacts unearthed, whether they are bronze or pottery, are mostly fus, mous, zengs, pots, etc. The most characteristics of these utensils are deep belly and round bottom. Judging from the most unearthed fus and mous, they all have exposure, deep-belly, and round bottom, with one or two ring-shaped vertical ears, and the vertical ears are often decorated with rope patterns. This makes the whole object shape looked like several circles overlapped from the side, and they are round and integrated, which is very visually beautiful. The zeng used for steaming food belongs to the compounder, and its shape is like two round fous nested together. Of course, these artifacts are all formed for practical purposes, and they are also an adaptive strategy for the Ba people to the natural environment in which they live, but it can still be said that the Ba people's characteristics of looking circle as beauty are clearly revealed here.

Not only that, like those objects that are not suitable for making a circle, the Ba people also changed them into a curved form or a streamlined shape. For example, the higher-standard ship coffins in the Ba culture tombs are buried the upper aristocracy and the warrior class, and their funeral vessels and ship coffins also have curved bottoms, thus leaving high-end and low-center filling remains in the tombs (Edited by Sichuan Provincial Museum, 1960). Some of those tombs in the form of wooden coffins, which were influenced by the Central Plains and Chu culture, are also in the form of nearly ship coffins (Xiang, 2017). Among the weapons of the Ba culture, the willow-leaf shape with double arcuate blades is the most important feature, so that the swords, dagger-axes, and spears commonly known as the willow-shaped shape have become the most significant 
iconic objects in the Ba culture. Looking at the willow-shaped swords, this kind of weapon with a slightly curved side blade has no handle and no separation, and the entire sword body presents a smooth and streamlined shape, compared with the Central Plains and the southeast style bronze swords which have a straight body from the end to the blade, or has a handle and a partition. Compared with the Ba style swords, they are different styles and aesthetic perceptions. The unique tongue shape of dagger-axes in Ba culture is also different from that in the Central Plains. Its blade is more rounded, making the whole body look more like a pear shape from the side, so that the whole body can be used for cutting or chopping. To a certain extent, it also weakened its killing atmosphere as a weapon for killing and added some smart styles. Chunyu is another commonly-used functional artifact in Ba culture. Its main purpose is to knock the team forward and back in combat. The entire shape of the chunyu looks somewhat like an inverted horn, which is quite different from the musical instruments such as the bronze chimes in the Central Plains. It also presents a round and smooth line of beauty. In general, although these bronze objects of the Ba people have practical purposes, it is undeniable that they fully reflect the characteristics of the $\mathrm{Ba}$ people's beauty of roundness and radian.

The Ba people's aesthetic characteristics of roundness are not only reflected in the utensils they use, but also in their daily lives. Although Ba people's dances, such as Bayu dance, no longer exist, they can still be inferred from the dances of Tujia people of Ba people's descent. According to the existing dances and historical records of Tujia people, there are Maogus, Muddymen dance, Bayu dance, funeral dance, Hand-waving dance, eight-treasure copper bell dance, etc., which are relatively close to their times. Most of these dances need to bend both upper and lower limbs at the same time in the process of dancing, and do dance movements such as curve displacement and arc swing. A remarkable feature of these movements is that they all have a certain degree of curvature and use of strength in the flashing movement. The movements are both rigid and soft. This is very different from the upright dance form in Central Plains and other regions, which gives it a unique curvaceous beauty. In particular, funeral dances and Hand-waving dances, which are considered to have typical Tujia dance styles, are known for their unique dance form movements. This aesthetic character seems to be related to the objective environment in which the Ba people live and the historical accumulation of their living habits. Although we have been unable to explore the real situation behind them and the historical development context, we can still learn from these artifacts and dance moves experience the relentless pursuit of beauty embodied by the Ba people in face of a severe living environment.

\section{The Beauty of Compatibility from Diverse Sources}

$\mathrm{Ba}$ region is in a place where various cultures intersect. The Ba culture was constantly affected by various cultures in the surroundings and actively absorbed 
them. The solemn beauty of the Central Plains culture, the dexterous beauty of the Chu culture, and the exotic beauty of the Shu culture are all reflected in the $\mathrm{Ba}$ culture and occupy a place. For example, the bronze gifts unearthed in the $\mathrm{Ba}$ cultural area obviously have the characteristics of the Central Plains and Chu culture. These artifacts were unearthed in the same Ba people's tombs together with typical Ba people's weapons and other artifacts, expressing this tolerant cultural absorption attitude. Of course, these cultures also include the characteristics of Ba culture. The unique geographical and human environment also allows Ba culture to obtain the space for survival among the strong cultures, and develop it to form a unique Tujia culture in the same vein.

The imprints of various cultural beauty converge in $\mathrm{Ba}$, and they are combined with excitement. Some retain their own unique art forms, while others integrate with each other to form a unique Ba cultural aesthetic tradition, and affect other than utensils, singing and dancing, such as architecture, textile and other aspects. All of these have become unique traditions and models of the Ba culture. This integration also makes the Ba culture show an optimistic mental state and aesthetic interest. It can also be said that it is the place where the Ba people live in a variety of cultures, and the Ba people's own spiritual traits have formed them into a spirit of revolutionary optimism similar to that of warlike, and the impression of beauty is also different from elsewhere of China. With the development of the times, the Ba people and Ba culture have either been merged into Han nationalities and cultures, or they have independently inherited the Tujia culture with distinct characteristics, or they have gradually disappeared into the long river of history because they are no longer appropriate. No matter how the current affairs change, the Ba culture still influences and nourishes this land with its special cultural charm, and survives and develops stubbornly. Its unique aesthetic characteristics are also shining in the forest of national aesthetics.

The $\mathrm{Ba}$ culture is a regional culture that has received more attention. Its production and development undoubtedly affect the formation of unique aesthetic characteristics and concepts in the region, and the research and development in this field are conducive to a deeper understanding of the cultural genes and heritage of the region, in order to better serve the local production and life, and add new examples to Chinese aesthetics.

\section{Fund Project}

The general project of Ba Cultural Aesthetics Research (18Y026), the Research Center for Aesthetics and Aesthetic Education, Sichuan Normal University.

\section{Conflicts of Interest}

The author declares no conflicts of interest regarding the publication of this paper.

\section{References}

Edited by Sichuan Provincial Museum (1960). Excavation Report of the Boat Coffins in 
Sichuan Province. Beijing: Cultural Relics Publishing House.

Hegel (1979). Aesthetics (Vol. 1). Translated by Zhu Guangqian. Beijing: Commercial Press.

Shao, X. H. (2005). History of Painting Arts in the Yangtze River Area. Wuhan: Hubei Education Press.

Wei, Z. (1973). The History of Sui Dynasty, Geography Records (Vol. 31). Beijing: Zhonghua Book Company.

Xiang, M. W. (2017). Archaeological Perspective on Ba's and Shu's Ancient Histories. Doctor's Thesis, Changchun: Jilin University.

Yu, W. Y. (2018). A Preliminary Study of the Pre-Qin Archaeological Culture in the Middle and Lower Reaches of the Jialing River. Master's Thesis, Chongqing: Chongqing Normal University. 